\title{
Prospects of using Lachancea thermotolerans yeast in winemaking
}

\author{
Irina Peskova ${ }^{1, *}$, Tatiana Tanashchuk ${ }^{1}$, Elena Ostroukhova ${ }^{1}$, Evgenij Slastya ${ }^{1}$, Svetlana Levchenko ${ }^{1}$, and Natalia Lutkova $^{1}$ \\ ${ }^{1}$ All-Russian National Research Institute of Viticulture and Winemaking "Magarach" of the RAS, Russian Federation
}

\begin{abstract}
In connection with global warming, study to find new technological solutions that allow to obtain wines characterized by a lower ethanol content and balanced in the acids and sugars content is relevant.One of the solutions is to use Lachancea thermotolerans yeast, which can metabolize some of the hexoses into the lactic acid. In the present work the comparative studies of the chemical composition of wines from grape cultivar Cabernet Sauvignon and Crimean autochthonous cultivars Kefesia and Ekim kara, obtained using Saccharomyces and Lachancea thermotolerans yeasts, were investigated. Analytical studies were performed using HPLC. Experimental wines obtained using L. thermotolerans showed a decrease in ethyl alcohol content by $5-11 \%$ and $\mathrm{pH}$ values by $0.10-0.32$ unit sand an increase in the concentration of titratable acids an average 1.3 -fold and glycerol concentration by $30 \%$ compared to the control obtained at S. cerevisiae. In wines obtained using L. thermotolerans, the acetic acid content did not exceed $0.01 \mathrm{gL}-1$. The investigated wines were distinguished by their balanced and velvety taste. The results achieved indicate that the use of $\mathrm{L}$. thermotolerans yeast is promising for improving the quality of the wine production, including those with organic status.
\end{abstract}

\section{Introduction}

Traditionally, the main microorganisms used in the wine production are Saccharomyces yeasts. In the last decade, the biotechnological potential of members of other yeasts genus has attracted special attention of scientists [1-4]. The experience of using these microorganisms showed the possibility of their use to adjust the acidity of wine, its aroma, the content of glycerin, ethanol, mannoproteins, anthocyanins, polysaccharides [5-10], as well as to reduce substances that affect product safety ochratoxin A [11], ethyl carbamate and biogenic amines [12].

One of these microorganisms is Lachancea thermotolerans yeast (formerly Kluyveromyces thermotolerans). This species is widespread in nature and is a common representative of the grape microflora [13-18]. The greatest interest for winemaking is the ability of this species to synthesize lactic acid during alcoholic fermentation [17]. Several cases recorded a lactic acid concentration increase to $16 \mathrm{gL}^{-1}$ during must fermentation on $L$. thermotolerans [19], while $S$. cerevisiaeare capable to synthesize no more than $0.4 \mathrm{gL}^{-1}$ of lactic acid during must fermentation [20]. The increase in titratable acidity (due to the formed lactic acid) has a positive effect on the microbial stability and organoleptic characteristics of wine. A L. thermotolerans feature is the ability to reduce the level of ethanol in wine due to the metabolism of a part of hexoses into lactic acid [21], which is especially important during processing grapes with high sugar content due to climate change. In addition, the use of $L$. thermotolerans increases the concentration of glycerin, decreases the concentration of acetic acid, which has a beneficial effect on the taste of wine; transformation of the aromaforming complex [5, 21-26].

Despite the fact that under the conditions of winemaking $L$. thermotoleranscan actively ferment sugars and produce up to $13.6 \%$ vol. ethanol [27], members of this species do not always realize a complete fermentation of sugars. In this regard, they are most often used in combination with $S$. cerevisiae [17]. However due to the antagonism between $S$. cerevisiae and L. thermotolerans, the result of combined use depends on several factors - the amount of nutrients, the presence of toxic compounds, etc. [22, 23, 28].

This article presents the results of the study of the influence of L. thermotolerans on the complex of organic acids, ethanol and glycerin content in red wines from grapes cultivars growing in the South Coast zone of Crimea.

\section{Materials and methods}

\subsection{Wine samples preparation}

Experimental studies were carried out on wines obtained under micro-winemaking conditions from grapes of the Crimean autochthonous cultivars (Ekim kara (Ek) and Kefesia (Kef)) and Cabernet Sauvignon (CS) cultivar growing on the Crimean Peninsula (harvest 2020). The

\footnotetext{
*Corresponding author: yarinka-73@mail.ru
} 
choice of grape cultivars is due to the following factors. Cabernet Sauvignon is the most common wine cultivar with colored berries in Crimea. At the same time, in the Crimean winemaking, there is a pronounced tendency to expand the use of autochthonous grape cultivars, one of the features of which is a rapid decrease in the content of titratable acids during maturation [29]. The indicators of the chemical composition of grapes batches are presented in Table 1, according to which the mass concentration of sugars varied from 18.6 to $21.8^{\circ}$ Brix, titratable acids - from 3.6 to $5.5 \mathrm{~g} \mathrm{~L}^{-1}$.

Table 1. Indicators of grapes*.

\begin{tabular}{|l|l|l|l|}
\hline \multirow{2}{*}{} & \multicolumn{3}{|c|}{ Grape cultivars } \\
\cline { 2 - 4 } & Ekim kara & Kefesia & $\begin{array}{c}\text { Cabernet } \\
\text { Sauvignon }\end{array}$ \\
\hline $\begin{array}{l}\text { Growth } \\
\text { place }\end{array}$ & $\begin{array}{c}\text { Solnech- } \\
\text { naya dolina } \\
\text { village }\end{array}$ & $\begin{array}{c}\text { Morskoe } \\
\text { village }\end{array}$ & $\begin{array}{c}\text { Privetnoe } \\
\text { village }\end{array}$ \\
\hline $\begin{array}{l}\text { Total sugar, } \\
{ }^{\circ} \text { Brix }\end{array}$ & $18.6 \pm 0.7$ & $19.6 \pm 0.7$ & $21.8 \pm 0.8$ \\
\hline $\begin{array}{l}\text { Concentrati } \\
\text { on, gL } \\
\text {-titratable } \\
\text { acids }\end{array}$ & $5.4 \pm 0.2$ & $3.6 \pm 0.1$ & $5.5 \pm 0.2$ \\
\hline -lactic acid & $0.18 \pm 0.007$ & $0.12 \pm 0.006$ & $0.29 \pm 0.01$ \\
\hline -malic acid & $0.41 \pm 0.02$ & $0.11 \pm 0.006$ & $2.16 \pm 0.08$ \\
\hline pH & $3.48 \pm 0.07$ & $3.72 \pm 0.07$ & $3.57 \pm 0.09$ \\
\hline$*$ arithmetic mean value \pm standard deviation (SD) \\
\hline
\end{tabular}

The wine production technology included crushing grapes, stems separation, mash sulfitationat the rate of $75 \pm 5 \mathrm{mgL}^{-1}$ and its fermentation at a temperature of $25 \pm 3^{\circ} \mathrm{C}$ with pomace mixing 7-8 times a day. Grape tannin-resistant yeast strains $S$. cerevisiae I-652 and I-25 [30] and L. thermotolerans from the Collection of Microorganisms for Winemaking of the Institute "Magarach" were used. Table 2 shows the options for using yeast strains in the preparation of control and tested wine batches. The amount of lactic acid formed by L. thermotolerans is determined by the moment of microorganisms inoculation [31]. Therefore, the tested samples were fermented both by single inoculation of $L$. thermotolerans and by sequential inoculation of $S$. cerevisiae and L. thermotolerans. Population inoculated of yeast must be $>\log 6 \mathrm{CFUmL}^{-1}$. Microbiological control was executed at all stages of wine production.

Table 2. Features of the preparation of control and tested wines.

\begin{tabular}{|c|c|c|}
\hline $\begin{array}{l}\text { Grape } \\
\text { cultivar }\end{array}$ & Sample & Yeast strain \\
\hline \multirow{2}{*}{ Ekim kara } & Control (c) & S. cerevisiae (I-652) \\
\hline & Test (t) & L. thermotolerans \\
\hline \multirow[b]{2}{*}{ Kefesia } & Control & S. cerevisiae (I-652) \\
\hline & Test & $\begin{array}{l}\text { S. cerevisiae (I-652), at } \\
\text { alcohol concentration } 3 \% \text {, } \\
\text { L. thermotolerans was } \\
\text { inoculated }\end{array}$ \\
\hline \multirow{2}{*}{$\begin{array}{l}\text { Cabernet } \\
\text { Sauvignon }\end{array}$} & Control & S. cerevisiae (I-25) \\
\hline & Test & L. thermotolerans \\
\hline
\end{tabular}

\subsection{Analysis of the chemical composition of wine}

The mass concentration of organic acids, ethanol, and glycerol in grapes and wine was determined by HPLC using gel exclusion separation on a Supelcogel $610 \mathrm{H}$ column in a $0.01 \mathrm{~N}$ perchloric acid system, by spectrophotometry $(210 \mathrm{~nm})$ and refractometry on a Shimadzu LC20AD chromatograph Prominence (Japan). The mass concentration of titratable acids in wine was determined by wine sample direct titration with an alkali solution to a neutral $\mathrm{pH}$ reaction by a potentiometric method.

\subsection{Statistical data analysis}

Tested and control samples of wines were prepared in 23 replicates: the total amount of wine samples was 15 .

All chemical analyzes were performed in triplicate. The data were mathematically processed with the help of statistical software package SPSS Statistics 17.0.

The following figures and text show arithmetic mean value and standard deviation (SD).

\section{Results and discussion}

The study results showed that wines obtained using $L$. thermotolerans had a lower ethanol content in comparison with the control wine samples obtained using the $S$. cerevisiae. In the control wine from Crimean autochthonous cultivar Ekim kara, obtained using $S$. cerevisiae, ethanol content was $12.7 \pm 0.7 \% \mathrm{vol}$, in tested ones $-12.1 \pm 0.5 \%$ vol. Consecutive must fermentation with $S$. cerevisiae and L. thermotolerans also contributed to a decrease (in comparison with the control sample) in ethanol concentration in wine by $1.4 \%$ vol.

The content of titratable acids and especially the active acidity $(\mathrm{pH})$ of wine are important factors contributing to a stable product. According to the literature data, $\mathrm{pH} \geq 4.00$ does not protect wine from microbiological contamination even in the absence of residual sugar and a high ethyl alcohol concentration [32]. At such $\mathrm{pH}$ values, the concentration of the molecular form of sulfur dioxide, which ensures the microbial stability of wines, is no more than $0.5 \mathrm{mgL}^{-1}$, even during the concentration of free forms of sulfur dioxide is above $50 \mathrm{mgL}^{-1}$ [32]. A decrease in $\mathrm{pH}$ values to 3.5-3.7 promotes an increase in the level of the molecular form of sulfur dioxide while maintaining the lowest total concentration of sulfites in wine [32], which increases the microbiological safety of both the fermentation process and subsequent storage of wine. Figure 1 shows that in tested wines from Ekim kara and Cabernet Sauvignon, the $\mathrm{pH}$ values were $3.66 \pm 0.18$ and $3.74 \pm 0.15$, while in the control samples $-3.76 \pm 0.14$ and $4.03 \pm 0.14$, respectively. In the case of wines from Kefesia, despite an increase in titratable acidity by 1.3 times, the $\mathrm{pH}$ value in tested wines was $4.00 \pm 0.15$, while in control one $-4.16 \pm 0.18$. 

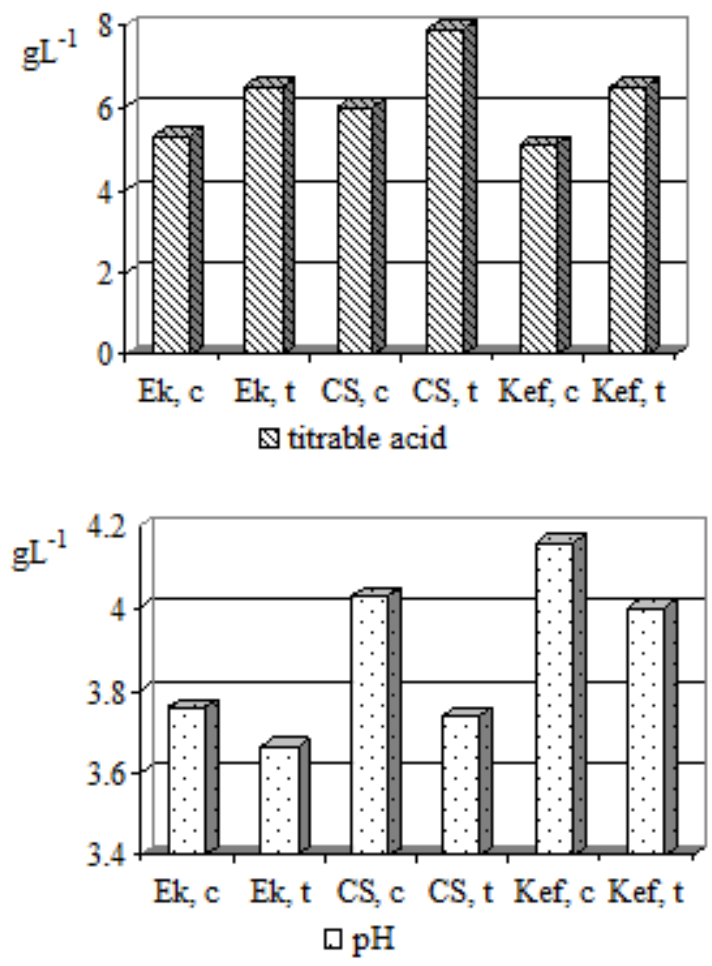

Fig. 1. Mass concentration of titratable acids and $\mathrm{pH}$ in wines obtained with the use of different yeast strains.

The concentration of titratable acids in wines obtained using L. thermotolerans was, on average, 1.3 times higher than in the control samples (Figure 1). The increase in the titratable acids concentration in the tested wines is associated with the formation of lactic acid by L. thermotolerans. The study of the dynamics of lactic acid concentration in the "grape-wine" chain showed that the use of $L$. thermotolerans promoted its increase in wine relative to that in grapes by an average in 4.2 times in Ekim kara and in 12.3 times in Cabernet Sauvignon. At the same time, carrying out fermentation using Saccharomyces yeast strains contributed to an increase in the concentration of lactic acid by 2.3 and 1.8 times, respectively. As can be seen in Figure 2, in wines obtained using L. thermotolerans, the concentration of lactic acid was $0.76 \pm 0.06 \mathrm{gL}^{-1}$ (Ekim kara) and $3.57 \pm$ 0.21 (Cabernet Sauvignon) $\mathrm{gL}^{-1}$, which, respectively, on average 1.8 and 7 times higher than in the control samples obtained using $S$. cerevisiae. At this stage of study, the successive mash fermentation with $S$. cerevisiae and L. thermotolerans (Kefesia) did not lead to the accumulation of lactic acid, the concentration of which in the control sample was $0.23 \pm 0.01 \mathrm{gL}^{-1}$; in the tested one $-0.24 \pm 0.02 \mathrm{gL}^{-1}$. Perhaps this was due to the antagonistic interactions of these strains, as well as the accumulation of a number of substances (for example, ethanol) that had a depressing effect on $L$. thermotolerans and others $[32,33]$.
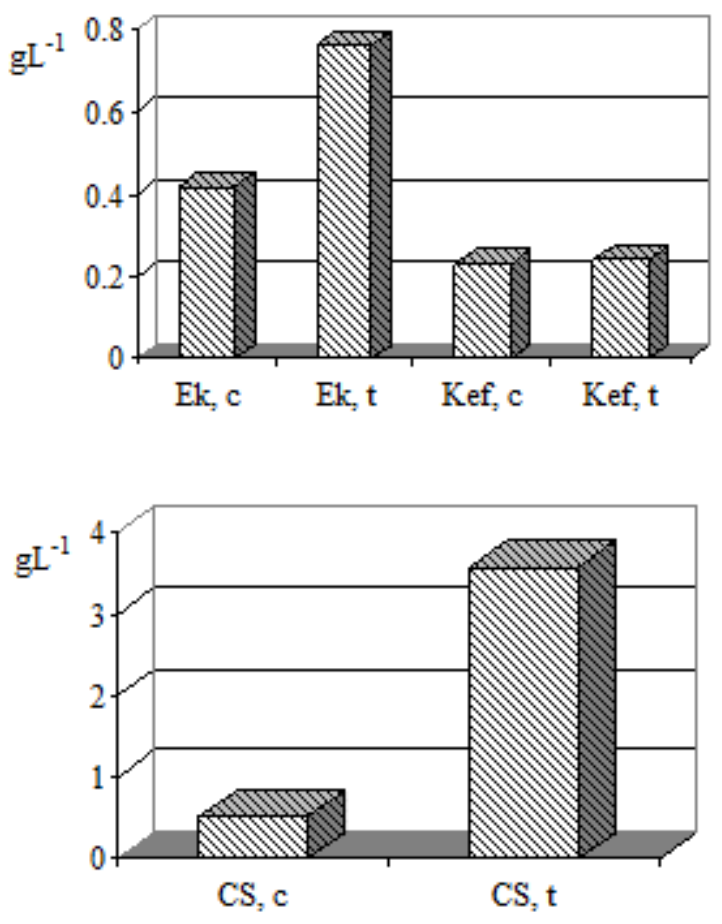

Fig. 2. The content of lactic acid in wine obtained using different yeast strains.

It is known that $S$. cerevisiae are characterized by a low ability to metabolize extracellular malic acid, which is associated with the lack of a specific transport system for malate; low affinity of decarboxylating malate dehydrogenase for the substrate, localization of the enzyme in mitochondria [35]. At the same time, the degree of utilization of malic acid is determined genetically and varies depending on the yeast strain [36]. L. thermotolerans more actively use extracellular malic acid in their metabolism and are able to utilize from 8 to $26 \%$ of the substance $[21,37]$. As can be seen from the data presented in Figure 3, the concentration of malic acid in wines obtained from Cabernet Sauvignon and Kefesia using L. thermotolerans was 1.1 and 1.2 times lower than in the control samples, respectively. In the case of wines from Ekim kara, the use of $L$. thermotolerans led to an increase in the concentration of malic acid by 1.2 times in comparison with the control sample. This fact requires further study.

In the tested wines from Ekim kara and Cabernet Sauvignon, succinic acid content increased relative to the control wines by an average of 1.2 times, reaching 1.48$2.01 \mathrm{gL}^{-1}$. On the contrary, in the wines from Kefesia, obtained using $L$. thermotolerans, its concentrationa decreased by $12 \%$ (up to $1.57 \pm 0.06 \mathrm{~g} \mathrm{~L}^{-1}$ ) compared with the value of the indicator in the control samples. 


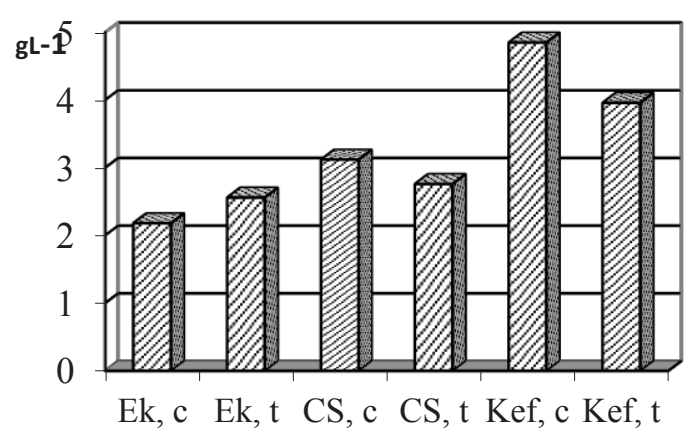

Fig. 3. Malic acid content in wines obtained using different yeast strains.

The concentration of acetic acid in control and tested wines varied from 0.01 to $0.19 \mathrm{~g} \mathrm{~L}^{-1}$.

In wines obtained using $S$. cerevisiae, the glycerol content ranged from 6.9 to $7.5 \mathrm{gL}^{-1}$. The use of $L$. thermotolerans led its concentration to increase in Cabernet Sauvignon wines by $30 \%$ and amounted to $9.5 \pm 0.3 \mathrm{gL}^{-1}$. In tested wines from other grape cultivars, the glycerin content remained at the level of the control samples.

Organoleptic testing of wines showed that the tested ones were distinguished by freshness, better balance and velvety taste.

\section{Conclusion}

Thus, the ability of $L$. thermotolerans to regulate the titratable acidity and $\mathrm{pH}$, reduce the concentration of ethanol in wines by utilizing part of the sugars to lactic acid synthesis, increase the glycerol content and synthesize small amounts of acetic acid indicates the prospects of using this yeast species for production of quality wine products, including those with organic status. The study results are especially relevant now in connection with global warming, which results in an increased content of sugars and decreased titratable acids in grapes used for wine production, which negatively affects the quality of the finished product.

\section{References}

1. B. Padilla, J.V. Gil, P. Manzanares, Front Microbiol., 7 (411), 20 (2016)

2. C. Varela, Appl Microbiol Biotechnol., 100, 14 (2016)

3. L. Petruzzi, V. Capozzi, C. Berbegal, M.R. Corbo, A. Bevilacqua, G. Spano, M. Sinigaglia, Front Microbiol., 8 (995), 13 (2017)

4. A. Benito, F. Calderon, S. Benito, Singleton TL (ed) Methods molecular biology (Springer, Berlin, 2018)

5. E.K. Balikci, H. Tanguler, N.P. Jolly, H. Erten, Yeast, 33 (7), 9 (2016)

6. I. Belda, J. Ruiz, B. Beisert, E. Navascues, D. Marquina, F. Calderon, D. Rauhut, S. Benito, A. Santos, Int. J. Food Microbiol., 257, 9 (2017)
7. I. Belda, E. Navascues, D. Marquina, A. Santos, F. Calderon, S. Benito, Appl. Microbiol. Biotechnol., 99 (4), 12 (2015)

8. A. Contreras, C. Hidalgo, P.A. Henschke, P.J. Chambers, C. Curtin, C. Varela, Appl. Environ. Microbiol., 80 (5), 9 (2014)

9. A. Benito, F. Calderon, S. Benito, Molecules, 22 (5): 739, 14 (2017)

10. P. Domizio, Y. Liu, L.F. Bisson, D. Barile, Food Microbiol., 61, 14 (2017)

11. M.L. Ponsone, M.C. Nally, M.L. Chiotta, M. Combina, J. Kohl, S.N. Chulze, Biol. Control, 103, 8 (2016)

12. A. Benito, F. Calderon, F. Palomero, S. Benito, Molecules, 20 (6), 14 (2015)

13. E.S. Naumova, E.V. Serpova, G.I. Naumov, Biochemistry, 72 (12), 7 (2007)

14. K.C. Freel, A. Friedrich, J. Hou, J. Schacherer, Genome Biol. Evol., 6, 9 (2014)

15. H.A. Robinson, A. Pinharanda, D. Bensasson, Ecol. Evol., 6 (4), 15 (2016)

16. A. Hranilovic, M. Bely, I. Masneuf-Pomarede, V. Jiranek, W. Albertin, PLoS One, 12, 17 (2017)

17. N.P. Jolly, C. Varela, I.S. Pretorius, FEMS Yeast Res. 14, 23 (2014)

18. M. Sipiczki, Front. Microbiol., 7 (212), 17 (2016)

19. G. Banilas, G. Sgouros, A. Nisiotou, Microbiol. Res., 193, 10 (2016)

20. M. Sauer, D. Porro, D. Mattanovich, P. Branduardi, Biotechnol. Genet. Eng. Rev., 27, 23 (2010)

21. M. Gobbi, F. Comitini, P. Domizio, C. Romani, L. Lencioni, I. Mannazzu, M. Ciani, Food Microbiol., 33, 11 (2013)

22. F. Comitini, M. Gobbi, P. Domizio, C. Romani, L. Lencioni, I. Mannazzu, M. Ciani, Food Microbiol., 28, 10 (2011)

23. A. Benito, F. Calderon, F. Palomero, S. Benito, Food Technol. Biotechnol., 54, 10 (2016)

24. M.E. Beckner Whitener, J. Stanstrup, V. Panzeri, S. Carlin, B. Divol, M. Du Toit, U. Vrhovsek, Metabolomics, 12 (54), 25 (2016)

25. M.E. Beckner Whitener, J. Stanstrup, S. Carlin, B. Divol, M. Du Toit, U. Vrhovsek, Aust. J. Grape Wine Res., 23, 14 (2017)

26. G. Cordero-Bueso, B. Esteve-Zarzoso, J.M. Cabellos, M. Gil-Diaz, T. Arroyo, Eur. Food Res. Technol., 236, 15 (2012)

27. M. Ciani, L. Beco, F. Comitini, Int. J. Food. Microbiol., 108, 7 (2006)

28. V. Kemsawasd, P. Branco, M.G. Almeida, J. Caldeira, H. Albergaria, N. Arneborg, FEMS Microbiol. Lett., 362 (14), 8 (2015)

29. V. Volynkin, V. Likhovskoy, A. Polulyakh, S. Levchenko, E. Ostroukhova, I. Vasylyk, I. Peskova, Vitis: biology and Species (New York, 2020)

30. T.K. Skorikova, T.N. Tanashchuk, E.E. Travnikova, Magarach. Viticulture and Winemaking, 21 (2), 4 (2019)

31. A. Benito, F. Calderon, S. Benito, AMB Express AMB Express, 9 (1): 17, 8 (2019) 
32. A. Morata, I. Loira, W. Tesfaye, M.A. Banuelos, C. Gonzalez, J.A. Suarez Lepe, Fermentation, 4 (3), 53, 12 (2018)

33. A. Vilela, Fermentation, 5 (1), 27 (2019)

34. A. Mendes Ferreira, A. Mendes-Faia, Foods, 9 (9), 19 (2020)

35. H. Volschenk, H.J.J. Van Vuuren, M. ViljoenBloom, Curr. Genet., 43 (6), 379-391 (2003)

36. I.V. Peskova, E.V. Ostroukhova, N.Yu. Lutkova, O.V. Zaitseva, Magarach. iticulture and Winemaking, 22 (2), 5 (2020)

37. K. Kapsopoulou, A. Kapaklis, H. Spyropoulos, World J. Microbiol. Biotechnol., 21, 4 (2005). 